\section{Prof. Ulrich Mödder mit dem Rheinlandtaler ausgezeichnet}

Mediziner trieb Neukonzeptionierung und Modernisierung des Deutschen Röntgen-

Museums voran / LVR würdigt ehrenamtliches Engagement in Remscheid

Remscheid, 21. September 2016. Der Landschaftsverband Rheinland (LVR) hat Prof. em. Dr. med. Ulrich Mödder für seine Verdienste im Bereich der Regionalgeschichte in Remscheid mit dem Rheinlandtaler ausgezeichnet. Die Verleihung fand im Deutschen Röntgen-Museum Remscheid statt. Die Laudatio hielt Karin Schmitt-Promny, stellvertretende Vorsitzende der Landschaftsversammlung Rheinland und Mitglied des Landtags.

„Der Überzeugungskraft und dem Verhandlungsgeschick Ulrich Mödders haben wir es zu verdanken, dass sich das Deutsche Röntgen-Museum heute als Forschungszentrum für Groß und Klein, Alt und Jung, Laien und Wissenschaftler präsentiert“, lobte Karin Schmidt-Promny in ihrer Laudatio.

Der Radiologe treibt seit vielen Jahren mit hohem persönlichen Aufwand die Neukonzeptionierung und Modernisierung des Deutschen Röntgen-Museums in Remscheid voran. Als Mitglied und Vorsitzender des Vereins „Freunde und Förderer des Deutschen Röntgen-Museums in Remscheid-Lennep e.V." hat er viele Projektpartner für die Unterstützung und Finanzierung des Museums gewinnen können. „Ulrich Mödder hat mit politischem Gespür und Feingefühl die Landesregierung NRW, die Alfried-Krupp-von-und Halbach-Stiftung, die Nordrhein-Westfalen-Stiftung Naturschutz, Heimat- und Kulturpflege, den Landschaftsverband Rheinland und weitere Projektpartner gewinnen können. Die erhaltenen Fördermittel zur Realisierung des Masterplanes ermöglichten bereits im Jahr 2007 die feierliche Eröffnung des ersten Bauabschnitts“, führte die stellvertretende Vorsitzende der Landschaftsversammlung Rheinland in ihrer Würdigung aus.

Motiviert von der Begeisterung seines Vorsitzenden, hätte der Förderverein die Aufmerksamkeit unmittelbar auf den zweiten Bauabschnitt, der 2010 - in Zusammenarbeit mit der Stadt Remscheid vollendet und eröffnet werden konnte, gelenkt. Die Einweihung des Schauarchives wäre dann im vergangenen Jahr erfolgt, die Fertigstellung der Neukonzeption wäre für 2017 geplant, so Schmitt-Promny. Die Politikerin sieht in dem Mediziner „einen dieser besonderen Menschen, die es schaffen, aus einer persönlichen Leidenschaft heraus Großes zu erreichen“.
Der LVR verleiht den Rheinlandtaler seit 1976 an Persönlichkeiten, die sich um die Kulturpflege im Rheinland besonders verdient gemacht haben. Über die Vergabe der Auszeichnung entscheidet der Kulturausschuss der Landschaftsversammlung Rheinland.

Quelle: Landschaftsverband Rheinland (LVR)

\section{Ansprechpartnerin für redaktionelle Fragen: Katharina Landorff LVR-Fachbereich Kommunikation Telefon 0221 809-2527}
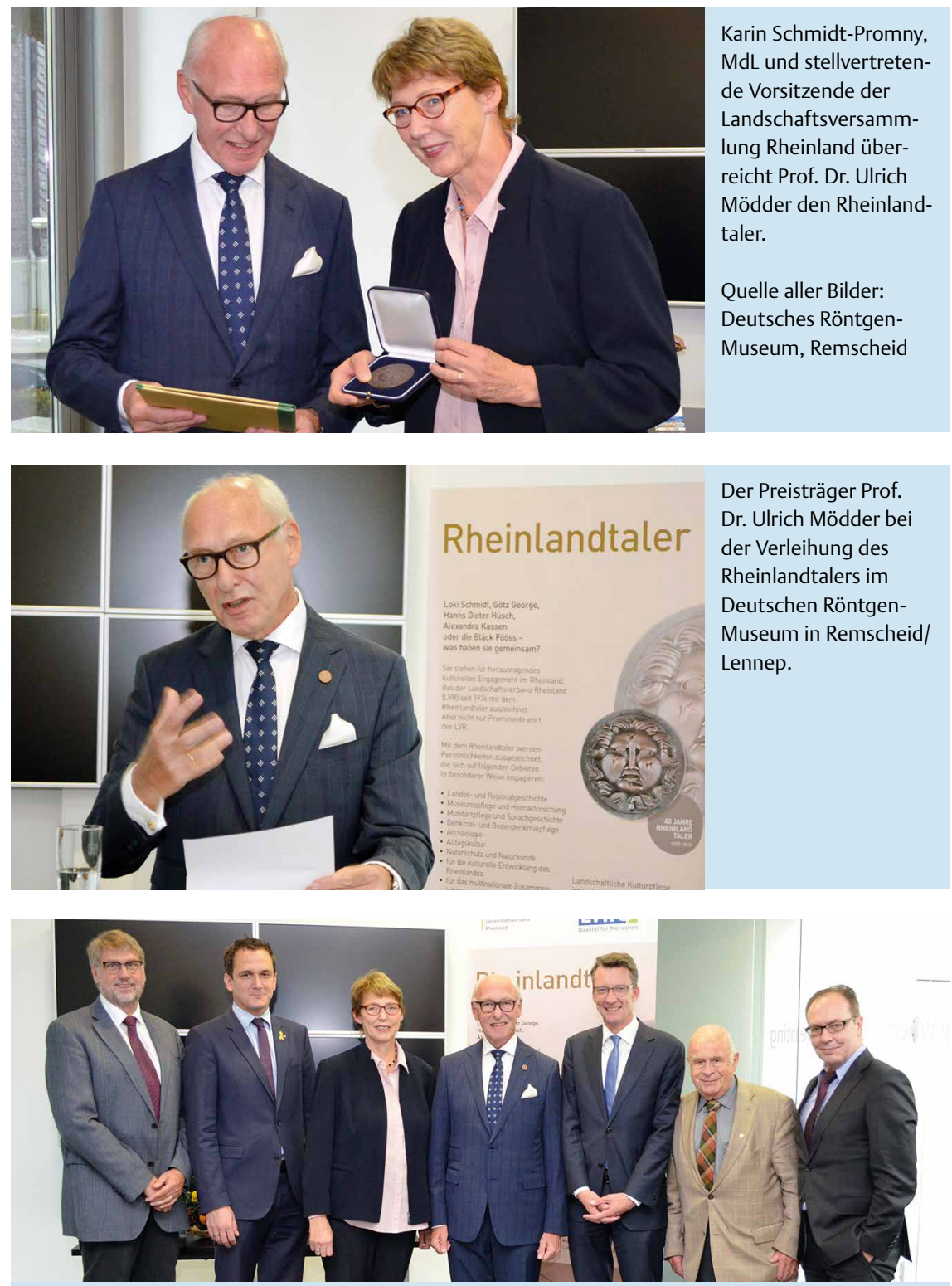

Bei der Verleihung (v.l.n.r.): Dr. Uwe Busch (Direktor des Deutschen Röntgen-Museums), Jens-Peter Nettekoven, MdL, Karin Schmidt-Promny, MdL, Stellv. Vorsitzende der Landschaftsversammlung Rheinland, Prof. Dr. Ulrich Mödder, Vorsitzender der Freunde und Förderer des Deutschen Röntgen-Museums, Sven Wolf, MdL, Prof. Dr. Christian Streffer, Ehrenvorsitzender der Gesellschaft der Freunde und Förderer des Deutschen Röntgen-Museums, Dr. Christian Henkelmann, Kulturdezernent Stadt Remscheid. 